\title{
Development of a variable resistance-capacitance model with time delay for urea-SCR system
}

\author{
Tan Feng ${ }^{\dagger}$, Lin Lü \\ Key Laboratory of High Performance Ship Technology of Ministry of Education, Wuhan University of Technology, Wuhan 430070, China
}

\begin{abstract}
Experimental research shows that the nitric oxides $\left(\mathrm{NO}_{\mathrm{x}}\right)$ concentration track at the outlet of selective catalytic reduction (SCR) catalyst with a transient variation of Adblue dosage has a time delay and it features a characteristic of resistance-capacitance (RC). The phenomenon brings obstacles to get the simultaneously $\mathrm{NOx}$ expected to be reduced and equi-molar ammonia available to SCR reaction, which finally inhibits $\mathrm{NO}_{x}$ conversion efficiency. Generally, engine loads change frequently, which triggers a rapid changing of Adblue dosage, and it aggravates the air quality that are caused by $\mathrm{NO}_{\mathrm{x}}$ emission and ammonia slip. In order to increase the conversion efficiency of $\mathrm{NO}_{\mathrm{x}}$ and avoid secondary pollution, the paper gives a comprehensive analysis of the SCR system and tells readers the key factors that affect time delay and RC characteristics. Accordingly, a map of time delay is established and a solution method for time constant and proportional constant is carried out. Finally, the paper accurately describes the input-output state relation of SCR system by using "variable RC model with time delay". The model can be used for a real-time correction of Adblue dosage, which can increase the conversion efficiency of NOx in SCR system and avoid secondary pollution forming. Obviously, the results of the work discover an avenue for the SCR control strategy.
\end{abstract}

Keywords: Diesel engine, Urea-SCR, Weight analysis, Time delay, Resistance-capacitance

\section{Introduction}

With the increasing demands for low engine emissions, reducing the $\mathrm{NO}_{\mathrm{x}}$ which is produced by heavy duty diesel vehicles has become one of the major tasks. Urea-SCR (selective catalytic reduction) systems possess an outstanding performance in $\mathrm{NO}_{\mathrm{x}}$ reduction, which can be served as a technology platform for further improvement. Therefore, urea-SCR system is regarded as the most promising approach to meet restricted emission standards [1].

Experimental researches showed that the $\mathrm{NO}_{\mathrm{x}}$ concentration tracked at the outlet of SCR catalyst with a transient variation of Adblue dosage had certain regularity (Fig. 1). After a sudden increase of Adblue dosage, the $\mathrm{NO}_{\mathrm{x}}$ concentration decreased at 3 seconds later, which means the time delay is encountered in SCR systems. Then, the $\mathrm{NO}_{\mathrm{x}}$ concentration decreased slowly and it became stable gradually in 80 seconds $\left(t_{1}\right)$. When the injection stopped, the $\mathrm{NO}_{\mathrm{X}}$ concentration increased to the original level in 70 seconds $\left(\mathrm{t}_{2}\right)$.

The track of $\mathrm{NO}_{\mathrm{x}}$ concentration features as a resistance-capacitance (RC) model, facing obstacles to obtain simultaneously $\mathrm{NO}_{\mathrm{x}}$ expected to be reduced and equi-molar ammonia available to SCR reaction, which finally inhibits $\mathrm{NO}_{\mathrm{x}}$ conversion efficiency. Generally, engine loads change frequently, triggering a rapid changing of Adblue dosage, which aggravates the air quality that are caused by $\mathrm{NO}_{\mathrm{x}}$ emission and ammonia slip.

The present research confirmed the problem which is discussed above. In order to increase the conversion efficiency of $\mathrm{NO}_{\mathrm{x}}$ and avoid secondary pollution, a lot of work have been done [2-5]. Bonfils et al. [2] proposed a lumping method for the SCR system. Zhang et al. [5] presented a method to combine neural network model with Fuzzy Fuzzy proportional-integral-derivative (PID) to To meet both $\mathrm{NO}_{\mathrm{x}}$ emission requirements and $\mathrm{NH}_{3}$ slip targets. However, the studies of embeddable models are relatively limited [6]. The existing embeddable models are not accurate enough to fully describe the transient response of $\mathrm{NO}_{\mathrm{x}}$ concentration and reveal the regularity of different factors affecting SCR system characteristics [7, 8].

Based on the weight analysis of the influencing factors on SCR system, the paper presents "variable RC model with time delay" to describe the input-output state relations of SCR system comprehensively. Such model can be used for a real-time correction of Adblue dosage, thus to creating an avenue for the SCR control strategy.
This is an Open Access article distributed under the terms of the Creative Commons Attribution Non-Commercial License (http://creativecommons. org/ licenses/by-nc/3.0/) which permits unrestricted non-commercial use, distribution, and reproduction in any medium, provided the original work is properly cited.
Received June 15, 2014 Accepted April 14, 2015

$\uparrow$ Corresponding author

Email: rhadamanthy@163.com

Tel: +86-134-76278498 Fax: +86-027-86550570 


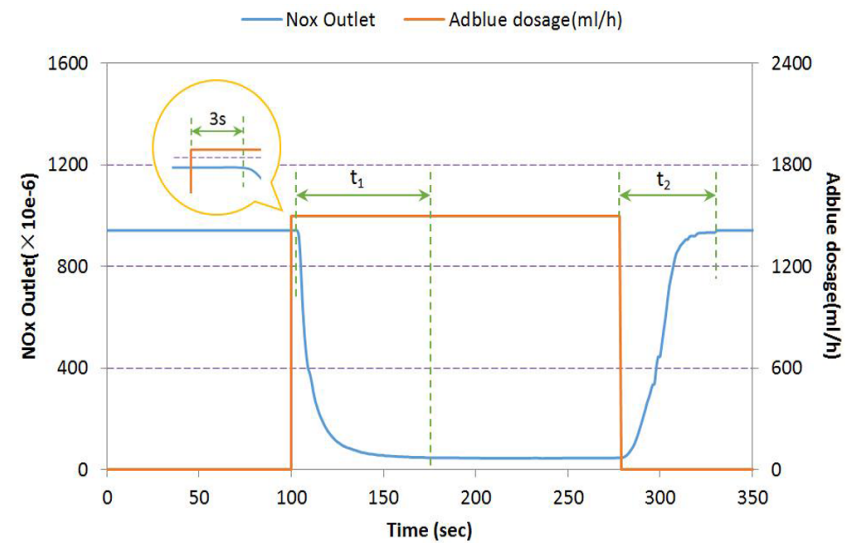

Fig 1. Outlet mole fractions of $\mathrm{NO}_{\mathrm{x}}$ during a transient change of Adblue dosage when the engine operated in steady state.

\section{Materials and Methods}

Both experimental and simulation research on the time-delay and RC characteristics of SCR system were implemented in the paper, and finally the "variable RC model with time delay" was obtained.

The experimental setup is consisted of a $4.75 \mathrm{~L}$ diesel engine, a $12 \mathrm{~L} \mathrm{~V}_{2} \mathrm{O}_{5}-\mathrm{WO}_{3} / \mathrm{TiO}_{2}$ catalyst, an Adblue dosing system and a Tianlan designed controller. The aftertreatment system was equipped with $\mathrm{NO}_{\mathrm{x}}$ sensors and exhaust temperature sensors at both inlet and outlet of the catalyst converter, an AVL AMA i60 emission analyzer and a Siemens ammonia analyzer at the tailpipe.

The process of urea-SCR system can be divided into atomization and decomposition process and catalytic reaction process. The paper established a 3D Adblue injection model to describe the first process, including the evaporation of droplets, secondary break-up, droplet-wall interaction and urea decomposition. A simplified 1D Adblue injection model based on the results of 3D model was also established to speed up the simulation. The urea-SCR model for the weight analysis was consisted of 1D Adblue injection model and 1D catalytic converter model (Fig. 2). After the estimation of kinetic parameters, the simulation results well agreed with the experiments.

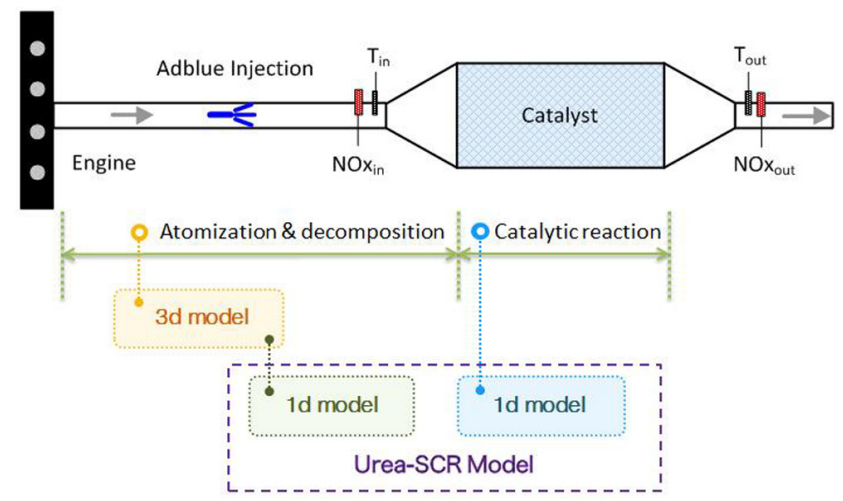

Fig. 2. The structure of Urea-SCR (selective catalytic reduction) model.

\section{Results and Discussion}

\subsection{Time Delay}

\subsubsection{Time delay of Adblue transportation}

Due to the time delay of Adblue transportation, the change of $\mathrm{NO}_{\mathrm{x}}$ concentration track at the inlet of SCR catalyst is obviously lagging behind the change of Adblue dosage. The state-of-the-art $\mathrm{NO}_{\mathrm{X}}$ sensors have cross-sensitivity to $\mathrm{NH}_{3}[9,10]$, which can be used to measure the transportation delay (Fig. 3).

The time delay of Adblue transportation is consisted of the lag time in injection pipe and exhaust pipe. The transportation delay of Adblue in injection pipe is related to the injection pressure, dosage and temperature of adlbue, and also the geometrical size of injection pipe. The transportation delay of Adblue in exhaust pipe caused by the atomization and decomposition process is influenced by exhaust mass flux and temperature, Adblue dosage and injection pressure, as well as the geometrical size of exhaust pipe. According to the simulation results of 3D Adblue injection model, the transportation delay of Adblue in exhaust pipe is 0.015 seconds (Fig. 4).

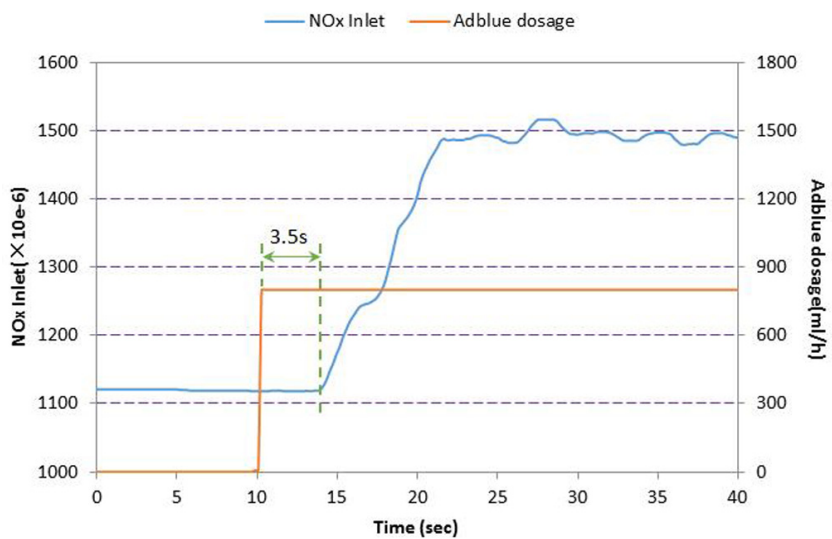

Fig. 3. The value of inlet $N O_{x}$ sensor during a transient change of Adblue dosage when the engine operated in steady state.
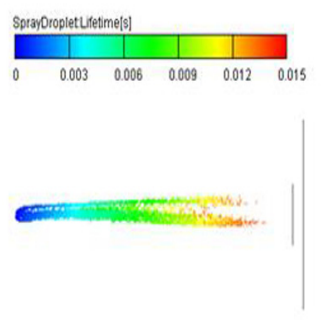

Fig. 4. The life time of droplets.

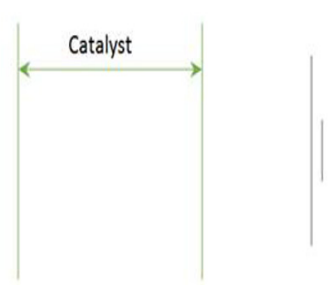

\subsubsection{Time delay of exhaust flow and catalytic reaction}

The value of $\mathrm{NO}_{\mathrm{x}}$ sensors at inlet and outlet of catalyst changes respectively corresponding to the change of Adblue dosage (Fig. 5). The lag time between two NOx sensors is consisted of the exhaust flow delay and reaction delay. 


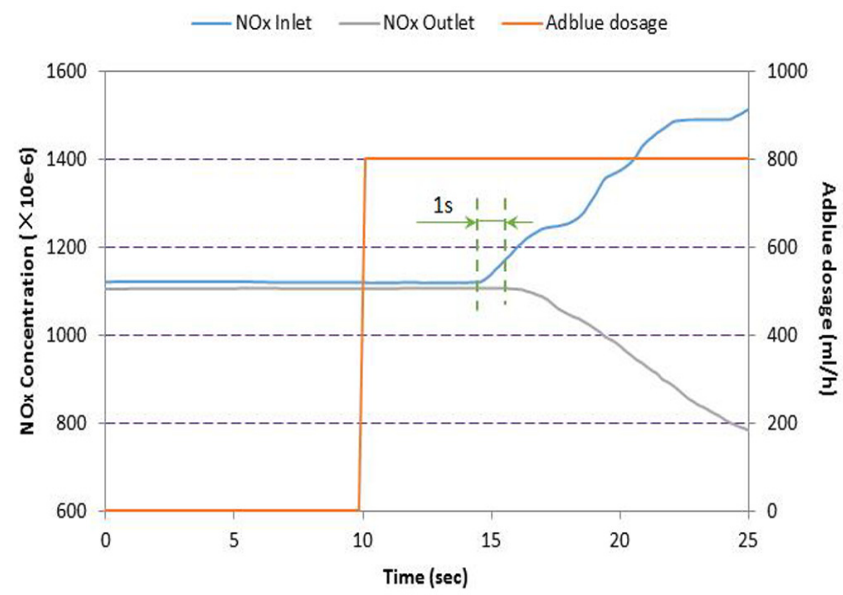

Fig 5. The value of $\mathrm{NO}_{x}$ sensor at inlet and outlet during a transient change of Adblue dosage when the engine operated in steady state.

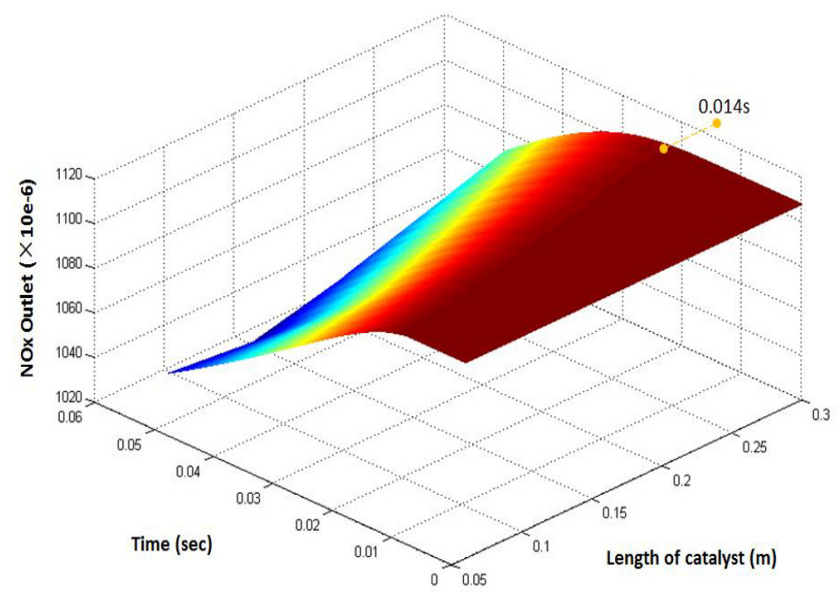

Fig. 6. Calculation of time delay in the catalyst.

The exhaust flow delay is related to exhaust flow, the temperature, and the structure of catalytic converter. In catalyst, $\mathrm{NH}_{3}$ is first absorbed at active site and then reacts with gas-phase $\mathrm{NO}_{\mathrm{x}}$ to form $\mathrm{N}_{2}$ and $\mathrm{H}_{2} \mathrm{O}$. The lag time of this process is influenced by exhaust flow and temperature, the gas composition and the size of catalyst. According to the simulation results of $1 \mathrm{D}$ catalytic converter model, the reaction delay in catalyst is $0.014 \mathrm{~s}$ (Fig. 6).

\subsubsection{Time-delay of different operations}

It can be concluded that the transportation delay of Adblue in the injection pipe and exhaust flow delay are the main compositions of time delay of urea-SCR system. Since the physical structure of injection pipe and catalytic converter are determined, the time delay of the system is mainly associated with exhaust flow and Adblue dosage. A map of time delay at different operations can be derived from various kind of experiments (Fig. 7).

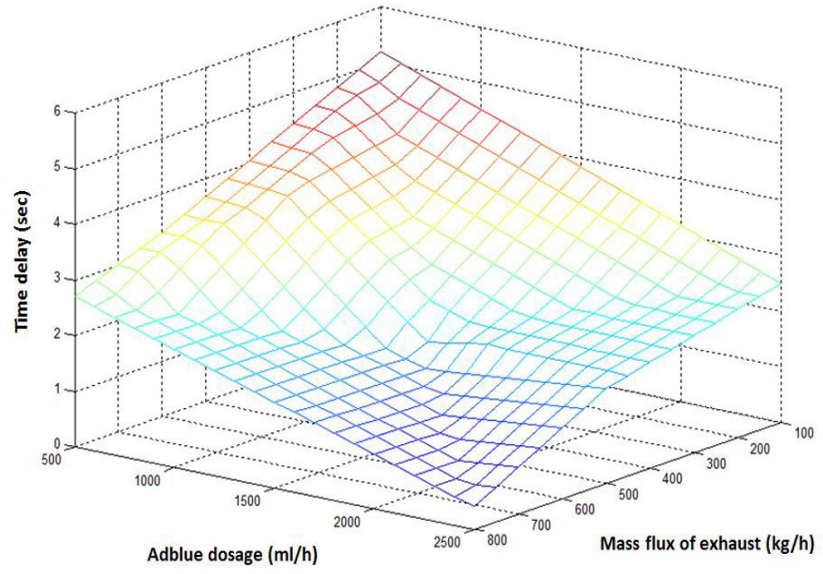

Fig. 7. The time delay of urea-SCR system.

\subsection{RC Characteristics}

\subsubsection{The weights of influencing factors}

The influencing factors of urea-SCR system discussed in this paper are consisted of four parts. The first is the properties of exhaust, which includes the gas composition, mass flux and temperature. The second refers to the relevant parameters of Adblue injection system, namely the injection quantity, Adblue temperature and the HCNO conversion efficiency. The third means the structure parameters of catalyst and the last one is the kinetic parameters of catalytic rate expressions.

The levels of influencing factors of exhaust properties were determined by the European steady Cycle (ESC) and European Transient Cycle (ETC) baseline tests (ESC baseline: $10.74 \mathrm{~g} / \mathrm{kW} \cdot \mathrm{h}$, ETC baseline: $10.38 \mathrm{~g} / \mathrm{kW} \cdot \mathrm{h})$. At the same time, the levels of factors in the second part were determined [11]. Furthermore, the levels of factors in the third part were determined on common commercial catalysts which have been widely used in the world [12]. What is more, the levels of kinetic parameters were determined on the estimation results at different exhaust temperature.

The weights of influencing factors on the $\mathrm{NOx}$ conversion efficiency, time $t_{1}$ and $t_{2}$ are shown in the Table 1 .

\subsubsection{The key factors of urea-SCR system}

The mean value of the weights was taken as an evaluation index in the paper. All the factors were evaluated and preliminary screened. A weight analysis of the screened factors was carried out and finally the critical elements were found out. The key factors are shown in the Table 2 and Table 3.

As shown in Table 2 and Table 3, the mass flux, temperature and $\mathrm{NO}_{\mathrm{x}}$ concentration of exhaust, the catalyst volume, the activation energy of $\mathrm{NH}_{3}$ ad/desorption and standard SCR reactions, and the Adblue dosage are the key factors of urea-SCR system.

The engine-out NOx level directly influences the development of urea-SCR system. The space velocity and activity of catalyst are affected by the exhaust mass flux and exhaust temperature. The $\mathrm{NO}_{\mathrm{x}}$ mass flux at the inlet is determined by the $\mathrm{NO}_{\mathrm{x}}$ concen 
Table 1. The weights of Influencing Factors

\begin{tabular}{|c|c|c|c|}
\hline \multirow{2}{*}{ Factors } & \multicolumn{3}{|c|}{ Weights } \\
\hline & $\mathrm{NO}_{\mathrm{x}}$ conversion efficiency & Time $t_{1}$ & Time $t_{2}$ \\
\hline Adblue dosage & 0.0883 & 0.0435 & 0.0195 \\
\hline Adblue temperature & 0.0302 & 0.0091 & 0.0089 \\
\hline Catalyst density & 0.0195 & 0.0200 & 0.0162 \\
\hline Catalyst volume & 0.0358 & 0.0620 & 0.0401 \\
\hline Coverage dependency & 0.0120 & 0.0151 & 0.0172 \\
\hline CPSI & 0.0230 & 0.0120 & 0.0227 \\
\hline Critical surface coverage of fast SCR (CSC_fast SCR) & 0.0127 & 0.0062 & 0.0359 \\
\hline CSC_slow SCR & 0.0423 & 0.0203 & 0.0258 \\
\hline CSC_standard SCR & 0.0150 & 0.0187 & 0.0116 \\
\hline Activation energy of fast SCR (E_fast SCR) & 0.0336 & 0.0287 & 0.0196 \\
\hline E_HCNO Hydrolysis & 0.0112 & 0.0141 & 0.0209 \\
\hline $\mathrm{E}_{-} \mathrm{NH}_{3}$ adsorption & 0.0141 & 0.0427 & 0.0384 \\
\hline E_NH $\mathrm{NH}_{3}$ desorption & 0.0386 & 0.0583 & 0.0412 \\
\hline E_NH $\mathrm{NH}_{3}$ oxidation & 0.0120 & 0.0316 & 0.0373 \\
\hline E_slow SCR & 0.0201 & 0.0315 & 0.0377 \\
\hline E_standard SCR & 0.0661 & 0.0176 & 0.0247 \\
\hline Exhaust mass flux & 0.0883 & 0.0512 & 0.0848 \\
\hline Exhaust temperature & 0.0701 & 0.0448 & 0.0513 \\
\hline HCNO conversion efficiency & 0.0292 & 0.0207 & 0.0130 \\
\hline Frequency factor of fast SCR (K_fast SCR) & 0.0100 & 0.0182 & 0.0158 \\
\hline K_HCNO hydrolysis & 0.0199 & 0.0302 & 0.0212 \\
\hline $\mathrm{K}_{-} \mathrm{NH}_{3}$ adsorption & 0.0114 & 0.0183 & 0.0195 \\
\hline $\mathrm{K}_{-} \mathrm{NH}_{3}$ desorption & 0.0199 & 0.0557 & 0.0110 \\
\hline $\mathrm{K} \_\mathrm{NH}_{3}$ oxidation & 0.0108 & 0.0229 & 0.0307 \\
\hline K_slow SCR & 0.0065 & 0.0281 & 0.0328 \\
\hline K_standard SCR & 0.0146 & 0.0086 & 0.0164 \\
\hline Length of catalyst & 0.0139 & 0.0198 & 0.0167 \\
\hline Max surface coverage fraction & 0.0170 & 0.0086 & 0.0138 \\
\hline Density of active sites & 0.0515 & 0.0534 & 0.0450 \\
\hline $\mathrm{NO}_{2}$ proportion & 0.0126 & 0.0098 & 0.0267 \\
\hline $\mathrm{NO}_{\mathrm{X}}$ concentration of exhaust & 0.0442 & 0.0550 & 0.0674 \\
\hline Outlet pressure & 0.0314 & 0.0174 & 0.0210 \\
\hline Specific heat of catalyst & 0.0209 & 0.0420 & 0.0251 \\
\hline Thermal conductivity of catalyst & 0.0163 & 0.0167 & 0.0290 \\
\hline Wall thickness & 0.0083 & 0.0142 & 0.0139 \\
\hline Washcoat thickness & 0.0284 & 0.0333 & 0.0270 \\
\hline
\end{tabular}

CPSI: channels per square inch $\left(\mathrm{in}^{-2}\right), \mathrm{CSC}$ : critical surface coverage, E: activation energy $\left(\mathrm{J} \cdot \mathrm{mol}^{-1}\right), \mathrm{K}:$ frequency factors $\left(\mathrm{m}^{4} \cdot \mathrm{mol} \cdot \mathrm{s} ; \mathrm{m}^{3} \cdot \mathrm{mol} ; \mathrm{m}^{-1}\right)$, SCR: selective catalytic reduction.

Table 2. Key Factors of $\mathrm{NOx}$ Transformation Efficiency

\begin{tabular}{ccc}
\hline Rank & Factor & Weight \\
\hline 1 & Exhaust mass flux & 0.2830 \\
2 & Adblue dosage & 0.1455 \\
3 & Exhaust temperature & 0.1160 \\
4 & E_standard SCR & 0.0876 \\
5 & $\mathrm{NO}_{\mathrm{x}}$ concentration of exhaust & 0.0805 \\
\hline
\end{tabular}

E: activation energy $\left(\mathrm{J} \cdot \mathrm{mol}^{-1}\right)$, SCR: selective catalytic reduction. tration and exhaust mass flux. Therefore, the mass flux, temperature and $\mathrm{NO}_{\mathrm{x}}$ concentration of exhaust play a very vital role on the $\mathrm{NO}_{\mathrm{x}}$ conversion efficiency, time $\mathrm{t}_{1}$ and $\mathrm{t}_{2}$.

The catalytic performance of catalyst is crucial to the urea-SCR system. The standard SCR reaction means a lot in the $\mathrm{NO}_{\mathrm{x}}$ reduction, so its activation energy has an obvious effect on the $\mathrm{NO}_{\mathrm{x}}$ conversion efficiency. Inside the catalyst, $\mathrm{NH}_{3}$ takes part in the SCR reaction only after the adsorption on the active sites, which refers to the reaction of $\mathrm{NH}_{3}$ ad/desorption, the density of active sites and the 
Table 3. Key Factors of Time $t_{1}$ and $t_{2}$

\begin{tabular}{|c|c|c|c|c|c|}
\hline \multicolumn{3}{|c|}{ Time $t_{1}$} & \multicolumn{3}{|c|}{ Time $t_{2}$} \\
\hline Rank & Factors & Weights & Rank & Factors & Weights \\
\hline 1 & Catalyst volume & 0.1347 & 1 & NOx concentration of exhaust & 0.1491 \\
\hline 2 & E_ $\mathrm{NH}_{3}$ desorption & 0.1104 & 2 & Exhaust temperature & 0.1371 \\
\hline 3 & Density of active sites & 0.0810 & 3 & Exhaust mass flux & 0.0951 \\
\hline 4 & $\mathrm{NO}_{\mathrm{x}}$ concentration of exhaust & 0.0774 & 4 & E_NH $\mathrm{NH}_{3}$ desorption & 0.0811 \\
\hline 5 & Exhaust mass flux & 0.0758 & 5 & Catalyst volume & 0.0793 \\
\hline 6 & Exhaust temperature & 0.0708 & & & \\
\hline 7 & Adblue dosage & 0.0658 & 6 & Density of active sites & 0.0779 \\
\hline 8 & E_ $\mathrm{NH}_{3}$ adsorption & 0.0651 & & & \\
\hline
\end{tabular}

E: activation energy $\left(\mathrm{J} \cdot \mathrm{mol}^{-1}\right)$.

catalyst volume have a great influence on the transient response of urea-SCR system.

The Adblue dosage which determines the concentration of $\mathrm{NH}_{3}$ and $\mathrm{HCNO}$ at the inlet has a great effect on the $\mathrm{NO}_{\mathrm{X}}$ conversion efficiency and time $t_{1}$ but little effect on time $t_{2}$.

\subsection{The Description of Urea-SCR System}

Based on the comprehensive analysis of urea-SCR system, the paper presents "variable RC model with time delay" to describe the characteristic of the system. The transfer function is calculated by Eq. (1):

$$
\mathrm{w}(\mathrm{s})=\frac{T_{\text {ratio }}}{\mathrm{RCs}+1} \cdot e^{-\tau \mathrm{s}}=\frac{T_{\text {ratio }}}{T_{R C} S+1} \cdot e^{-\tau s}
$$

Where, $\mathrm{R}$ is the value of resistance, $\mathrm{C}$ is the value of capacitance, $\mathrm{T}_{\mathrm{RC}}$ is the time constant, Tratio is the proportional constant, and $\tau$ is the time delay.

The parameter $\tau$ is derived from the interpolation of time delay map that is shown in Fig. 7. According to the results of weight analysis, the time constant and proportional constant are calculated by Eq. (2):

$$
T=\prod_{i}^{N}\left(A_{i} \cdot x_{i}^{2}+B_{i} \cdot x_{i}+C_{i}\right)
$$

Where, $\mathrm{N}$ is the number of key factors, $\mathrm{x}$ is the weight of key factors, A, B and C are state parameters.

As shown in Fig. 8, different $\mathrm{T}_{\mathrm{RC}}$ is used according to the trends

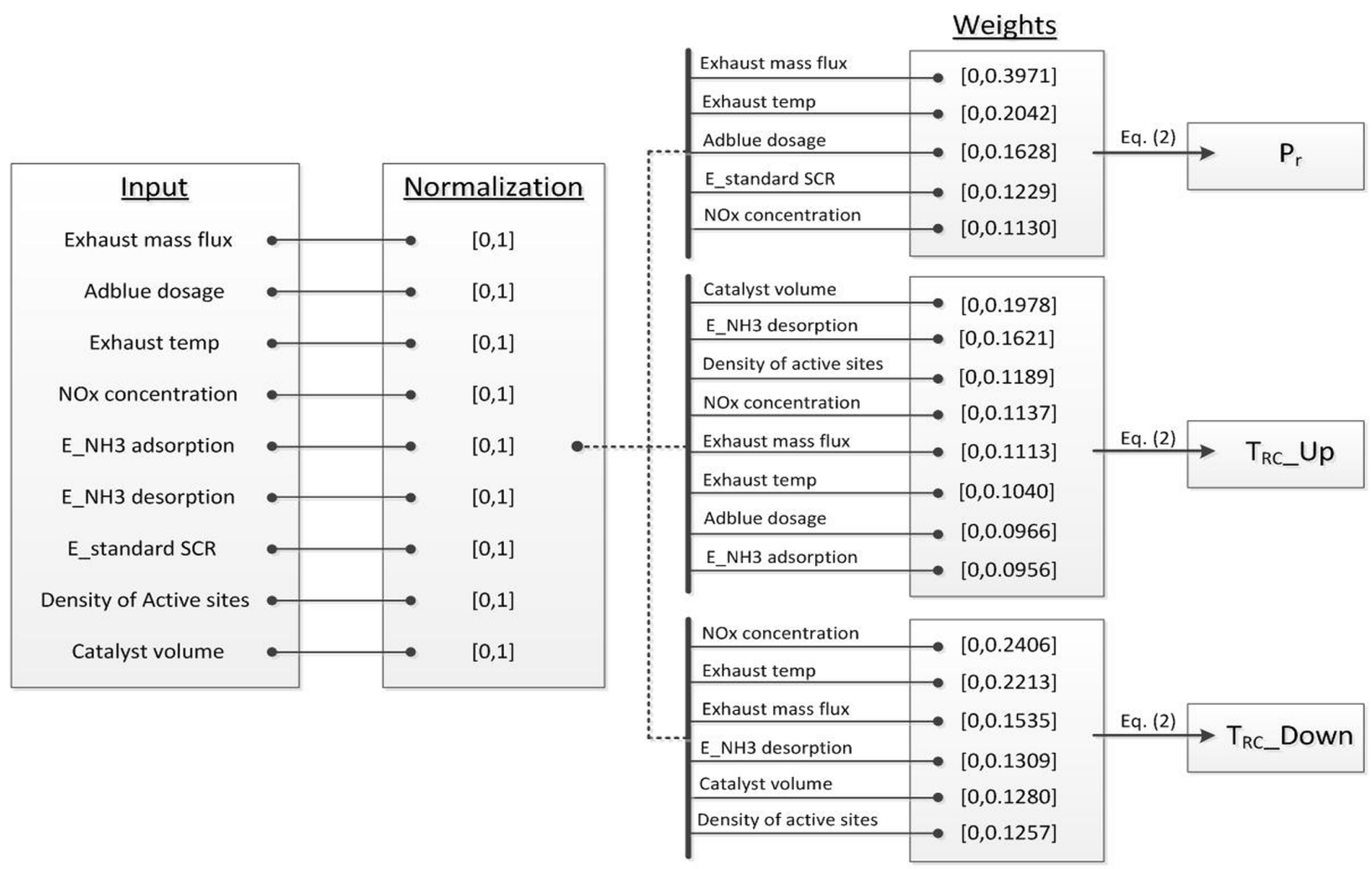

Fig. 8. The calculation process of $T_{R C}$ and $T_{\text {ratio }}$. 


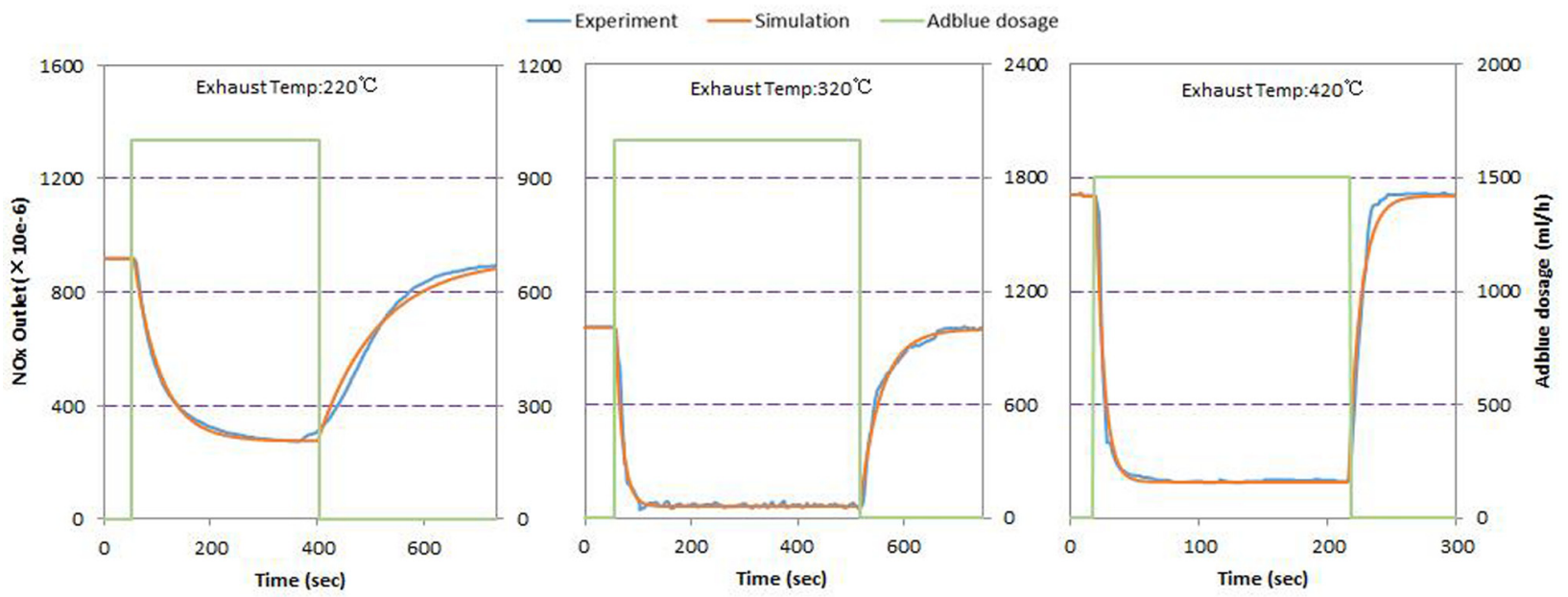

Fig. 9. Comparison between experiment and simulation results after the estimation.

of outlet $\mathrm{NO}_{\mathrm{x}}$ concentration.

After the estimation of state parameters by using genetic algorithm, the simulation results well agreed with the experiment (Fig. 9) and the error less than $0.5 \%$. The control strategies of Adblue dosage developed based on this model will have a better performance in keeping high $\mathrm{NO}_{\mathrm{x}}$ conversion efficiency and shortening the time $t_{1}$ and $t_{2}$, which can help to reduce $\mathrm{NO}_{\mathrm{X}}$ emission and avoid $\mathrm{NH}_{3}$ slip.

\subsection{Model-based Control of Urea-SCR System}

A model-based control strategy of urea-SCR system is presented in the paper (Fig. 10). The prediction of engine-out $\mathrm{NO}_{\mathrm{x}}$ is based on the $\mathrm{NO}_{\mathrm{x}}$ map that is derived from the universal performance curves. These steady-state values are corrected according to the change rate of speed and torque. What's more, the maximal $\mathrm{NO}_{\mathrm{x}}$ conversion efficiency (the $\mathrm{NH}_{3}$ slip is keeping at $10 \mathrm{ppm}$ ) at different SV and exhaust temperature are taken into consideration in the calculation of basic Adblue dosage. Also, the Adblue dosage must be modified during the sudden changes of engine operating conditions. The variable RC model is used for the prediction of system-out $\mathrm{NO}_{\mathrm{x}}$. According to the $\mathrm{NO}_{\mathrm{x}}$ target and prediction, the fuzzy controller gives the emendation of Adblue dosage. At last, a correction is made by the rapid increasing controller for preventing a greatly increase of Adblue dosage.

The model-based control strategy was verified by ETC and ESC test and the results were lower than Euro $\mathrm{V}$ emission standard limit $2.0 \mathrm{~g} / \mathrm{kw} \cdot \mathrm{h}$ (Fig. 11). Furthermore, as the key part in the SCR control, this model can be easily used in other strategies.

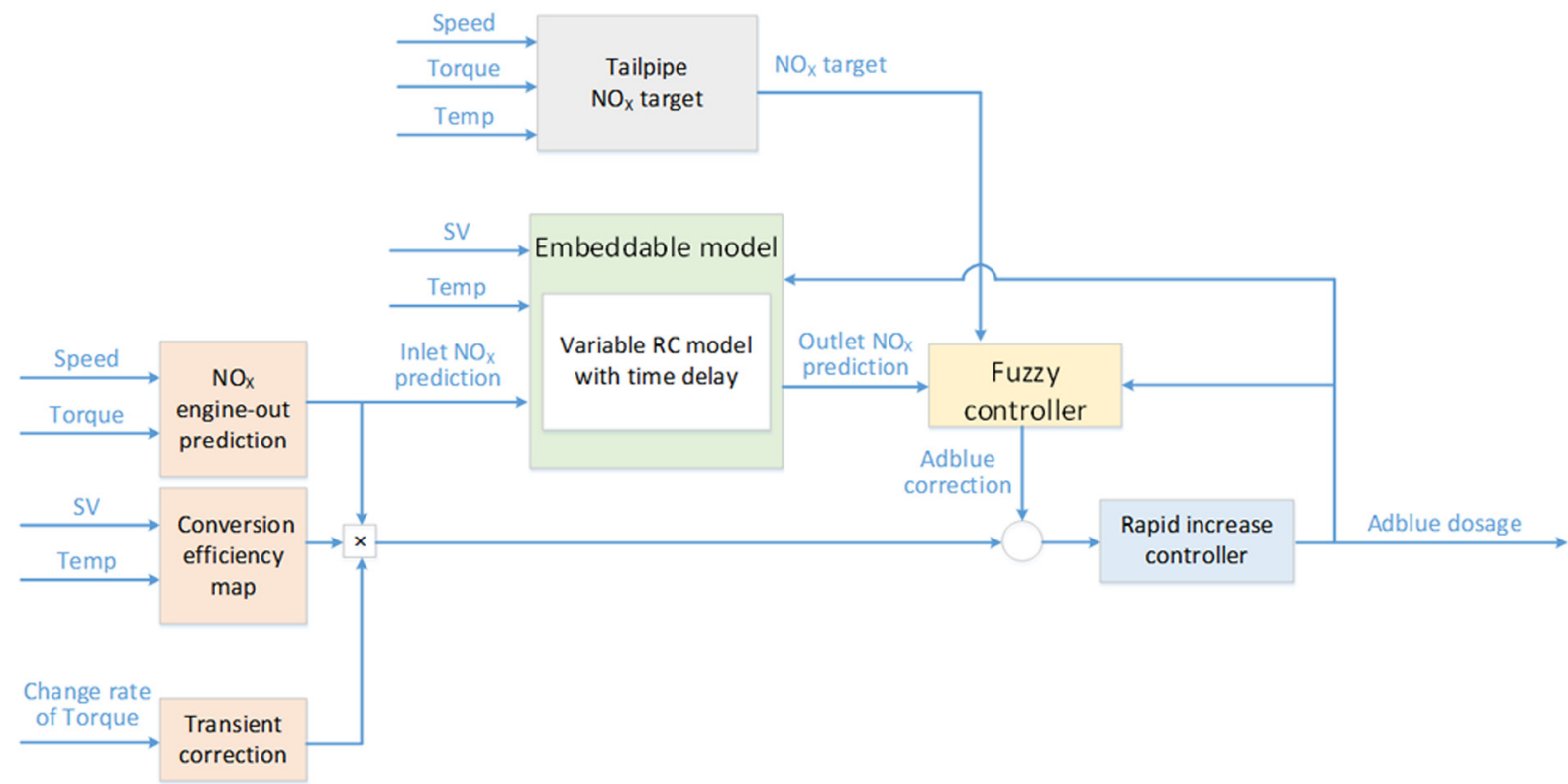

Fig. 10. Block scheme of model-based control strategy. 

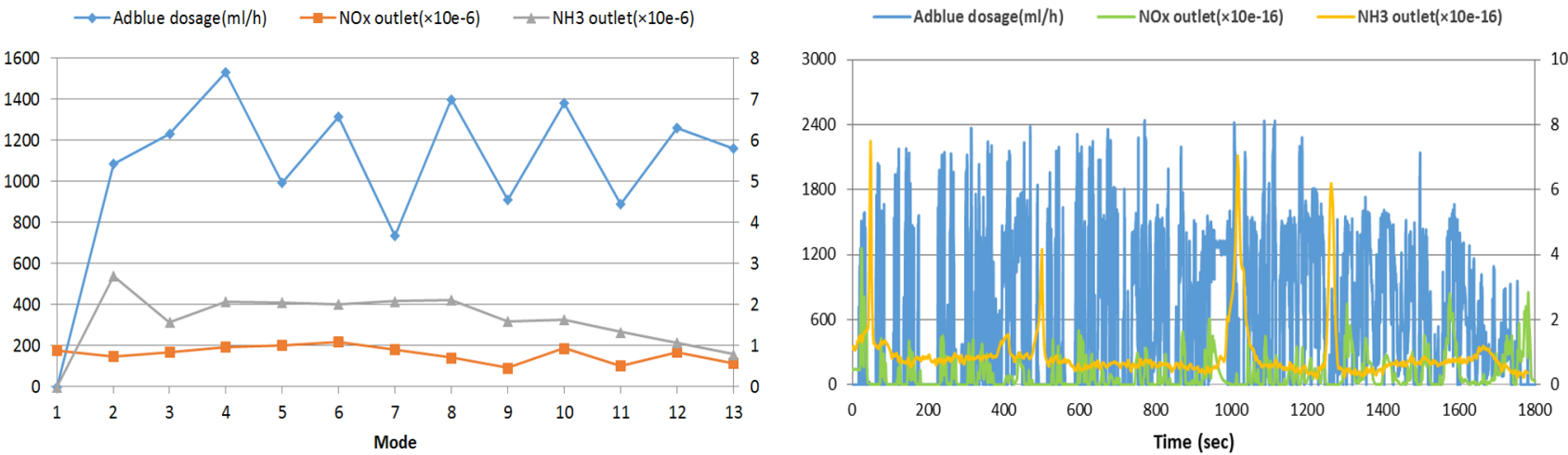

Fig. 11. (a) ESC and (b) ETC test results (The NOx specific emission of ESC and ETC were $1.64 \mathrm{~g} / \mathrm{kW} \cdot \mathrm{h}$ and $1.62 \mathrm{~g} / \mathrm{kW} \cdot \mathrm{h}$. The peak NH slip of ESC and ETC were $2.7 \times 10^{-6}$ and $\left.7.5 \times 10^{-6}\right)$. ESC: European steady cycle, ETC: European transient cycle.

\section{Conclusions}

The paper gives a comprehensive analysis of time delay of urea-SCR system, and the results show that the transportation delay of Adblue in injection pipe and exhaust flow delay are the main composition. A weight analysis of influencing factors is carried out and the result shows that the mass flux, temperature and $\mathrm{NO}_{\mathrm{x}}$ concentration of exhaust, the catalyst volume, the activation energy of $\mathrm{NH}_{3}$ ad/desorption and standard SCR reactions, and the Adblue dosage are the key factors of urea-SCR system.

Accordingly, a map of time delay is established and a solution method for time constant and proportional constant is carried out. Finally, the paper presents "variable RC model with time delay" to describe the input-output state relation of SCR system accurately and to reveal the regularity of different factors affecting SCR system characteristics. Moreover, this model can be used for a real-time correction of Adblue dosage, which can increase the conversion efficiency of $\mathrm{NO}_{\mathrm{x}}$ and avoid secondary pollution forming.

\section{Acknowledgments}

The research was supported by the National Natural Science Foundation of China (No. 51379165) and the Natural Science Foundation of Educational Department of Hubei government (No. 20520005). And the author appreciates the support of Key Laboratory of High Performance Ship Technology of Ministry of Education (Wuhan University of Technology).

\section{References}

1. Johnson T. Diesel emission control technology review. In: Diesel Engine-efficiency and emissions research (DEER) conference; 2006 Aug 20-24; Detroit.
2. Bonfils A, Creff Y, Lepreux O, Petit N. Closed-loop control of a SCR system using a $\mathrm{NO}_{\mathrm{x}}$ sensor cross-sensitive to $\mathrm{NH}_{3}$. J. Process Control 2014;24:368-378.

3. Lepreux O, Creff Y, Petit N. Model-based temperature control of a diesel oxidation catalyst. J. Process Control 2012;22:41-50.

4. Petit N. Model-based control of automotive engines and after-treatment devices. In: IFAC Joint conference; 2013 Feb 4-6; Grenoble.

5. Zhang SM, Tian F, Ren GF, Yang L. SCR control strategy based on ANNs and fuzzy PID in a heavy-duty diesel engine. Int. J. Automotive Technol. 2012;13:693-699.

6. Hsieh MF, Wang J. Development and experimental studies of a control-oriented SCR model for a two-catalyst urea-SCR system. Control Eng. Pract. 2011;19:409-422.

7. Su Y, Li J, Gao Y, Qu D. Applying Matlab/Simulink to study calculation of NOX efficiency of the SCR. Procedia Environ. Sci. 2011;11:996-1000.

8. Faghihi EM, Shamekhi AH. Development of a neural network model for selective catalytic reduction (SCR) catalytic converter and ammonia dosing optimization using multi objective genetic algorithm. Chem. Eng. J. 2010;165:508-516.

9. Hsieh MF, Wang J. Adaptive and efficient ammonia storage distribution control for a two-catalyst selective catalytic reduction system. J. Dyn. Sys. Meas. Control 2012;134:1201-1211.

10. Devarakonda M, Parker G, Johnson JH, Strots V. Model-based control system design in a urea-SCR aftertreatment system based on $\mathrm{NH}_{3}$ sensor feedback. Int. J. Automotive Technol. 2009;10:653-662.

11. Lü L, Wang L. Model-based optimization of parameters for a diesel engine SCR system. Int. J. Automotive Technol. 2013;14:13-18.

12. Schwämmle T, Bertsche F, Hartung A, Brandenstein J, Heidel B, Scheffknecht G. Influence of geometrical parameters of honeycomb commercial SCR-DeNOx-catalysts on DeNOx-activity, mercury oxidation and $\mathrm{SO}_{2} / \mathrm{SO}_{3}$-conversion. Chem. Eng. J. 2013;222:274-281. 